\title{
Rate, Pattern and Risk Factors of Hypothyroidism among Sudanese Pregnant Women
}

\begin{abstract}
Awad Alla Abd Elwahid Suliman'*, Maiada Abbas Albasha' ${ }^{2}$ Hajar Suliman Ibrahim ${ }^{3}$, Siddig Omer Mohammed Handady ${ }^{4}$, Awad Ali M. Alawad ${ }^{5}$

${ }^{1}$ Department of Obstetrics and Gynecology, Al Neelain University, Sudan

${ }^{2}$ Department of Internal Medicine Sudan, Sudan Medical Specialization Board

${ }^{3}$ Department of Obstetrics and Gynecology, Faculty of

Medicine, Al neelain University, Sudan

${ }^{4}$ Department of Obstetrics and Gynecology, Nahda

College, Sudan

${ }^{5}$ Faculty of Medicine, University of Medical Sciences and Technology, Sudan

*Corresponding author: Awad Ali M. Alawad, Faculty of Medicine, University of Medical Sciences and Technology, Sudan
\end{abstract}

Received: August 16, 2018; Accepted: September 18, 2018; Published: September 25, 2018

\section{Abstract}

Background: Thyroid disorders constitute one of the most common endocrine disorders seen in pregnancy. Hypothyroidism has been linked with poor reproductive health and pregnancy outcomes.

Objectives: To estimate the rate of hypothyroidism in a sample of Sudanese women during early pregnancy and to ascertain pattern and risk factors for hypothyroidism during pregnancy.

Methodology: It was descriptive cross-sectional and hospital-based study carried out at Omdurman Maternity Teaching Hospital, Khartoum State Sudan during the period March-November, 2017. Four hundred and ten (410) participants of pregnant women in first trimester of pregnancy $<13$ weeks of gestation, singleton pregnancy were incorporated. Data was collected by structure questionnaire. Laboratory testing of a blood sample for thyroid function was done. Demographic and clinical data concerning personal and family history (in first - and second-degree relatives) of thyroid disorders and/or other autoimmune diseases such as types1diabetes were recorded.

Results: Four -hundred-and-ten women were included, the age distribution ranged from 18 to 46 years with a mean (standard deviation) age of 28.65 years. The average ranges of TSH was (0.5-6.5 mIU/L) and T4 (10.5 - 20.4 $\mathrm{Pmol} / \mathrm{L}$ ) and there was slight fluctuation of the mean values of thyroid hormones according to trimester in euthyroid pregnant women. Subclinical and overt hypothyroidism was found in $56(13.7 \%)$ of women. Forty-three women $(10.5 \%)$ had subclinical hypothyroidism, thirteen (3.2\%) had overt hypothyroidism. The current study showed significant association between overt hypothyroidism and history of infertility, history of miscarriage, stillbirth, preterm deliveries, BMI and iodine deficiency at $(P$. value $<0.05)$.

Conclusion: Our study demonstrated a high prevalence of hypothyroidism among Sudanese pregnant women. Universal screening of pregnant women for thyroid dysfunction should thus be adopted throughout Sudan.

Keywords: Hypothyroidism; Pregnancy; Screening

\section{Introduction}

Detection of hypothyroidism early in pregnancy, before 13 weeks of gestation, and applying proper interventions can significantly reduce the possible adverse effects for the mother and fetus [1]. Thyroid disorder may be over looked in pregnancy because of nonspecific symptoms and hyper metabolic state of pregnancy. Physiological changes of pregnancy can stimulate thyroid disease. Prevalence of thyroid disorder during pregnancy has a wide geographic variation. Western literature shows a prevalence of hypothyroidism in pregnancy of $2.5 \%$ and hyperthyroidism in pregnancy has prevalence of 0.1 to $0.4 \%$ [2]. Overt Hypothyroidism defined as an elevated TSH level with a decreased level of free T4 [3-5]. Around 0.5\% of all pregnant women will have Overt Hypothyroidism $(\mathrm{OH})[5,6]$, The most common etiology of $\mathrm{OH}$ in pregnant women is chronic autoimmune thyroiditis (Hashimoto's thyroiditis). Other causes of $\mathrm{OH}$ include endemic Iodine Deficiency (ID), and prior radioactive iodine therapy or thyroidectomy. Untreated $\mathrm{OH}$ in pregnancy has consistently been shown to be associated with an increased risk for adverse pregnancy complications, as well as detrimental effects on fetal neurocognitive development [7]. Specific adverse outcomes associated with maternal $\mathrm{OH}$ include increased risks for premature birth, low birth weight, and miscarriage [8].

Subclinical Hypothyroidism ( $\mathrm{SH}$ ) $\mathrm{SH}$ is defined as an elevated TSH level with a normal level of circulating free T4. The prevalence of $\mathrm{SH}$ during pregnancy in the US is estimated to be $0.25-2.5 \%$ [9]. Symptoms of $\mathrm{SH}$, if present, are typically subtle, and might be attributed to pregnancy. Even in $\mathrm{OH}$, individuals there can be a major discrepancy between symptoms and thyroid status. The diagnosis of hypothyroidism can only be confirmed by laboratory tests of Thyroid Stimulating Hormone (TSH) and thyroid hormones thyroxine (T4) and triiodothyronine (T3) $[10,11]$. However, it is common in clinical practice to find pregnant women with TSH, T3 and T4 levels outside the reference range and there is a need for further evaluation to clarify the diagnosis and possible treatment [12]. The current study aimed to estimate the rate and pattern of hypothyroidism in a sample of Sudanese women during early pregnancy and to ascertain the risk 
Table 1: Thyroid stimulating hormone (TSH) and thyroxine (T4) measurements Among the total sample of 410 pregnant women.

\begin{tabular}{|c|c|c|c|c|c|c|}
\hline \multicolumn{4}{|c|}{ T4 level pmol /L } & \multicolumn{5}{c|}{ TSH level mlU/L } \\
\hline & $<0.49$ & $0.5-2.5$ & $2.6^{“}-4.5$ & $4.6-9.9$ & $>10$ & Total \\
\hline $9.1-10.5$ & 0 & 0 & $4^{*}$ & $8^{\star}$ & $1^{*}$ & 13 \\
\hline $10.6-20.4$ & 48 & 299 & $36^{\star *}$ & $7^{* *}$ & 0 & 390 \\
\hline$>20.4$ & 4 & 3 & 0 & 0 & 0 & 7 \\
\hline Total & 52 & 302 & 40 & 15 & 1 & 410 \\
\hline
\end{tabular}

${ }^{*}$ Overt hypothyroidism.

*Subclinical hypothyroidism.

factors for hypothyroidism.

\section{Materials and Methods}

It was descriptive cross-sectional hospital -based study carried out at Omdurman Maternity Teaching Hospital (Khartoum State), Sudan during the period March-November, 2017. A sample of 410 pregnant women in first trimester of pregnancy $<13$ weeks of gestation, singleton pregnancy willing to provide blood samples agree to participate in the study were selected. Those who were seriously ill or multiple pregnancy, known chronic disorders like diabetes and hypertension, previous bad obstetric history with known cause and patients planned follow-up and delivery in other hospital than study area were excluded. The participants were specifically questioned about the presence or absence of common symptoms associated with hypothyroidism.

All participants were instructed to undergo an interview to obtain a detailed history, and then undergo a clinical examination and laboratory testing of a blood sample for thyroid function. The participants were interviewed about age, education, occupation, gestational age, personal history of thyroid problems, family history of thyroid problems, diabetes mellitus and previous pregnancy complications.

After enrolment of participants, 5-7 $\mathrm{mL}$ of venous blood was drawn by venipuncture into a tube. The blood samples were stored in a secure refrigerator $\left(2-8{ }^{\circ} \mathrm{C}\right)$ laboratory testing. TSH and T4 measurements were conducted using a Micro Particle Enzyme Immunoassay (MEIA). The study based upon overt hypothyroidism was defined as a serum TSH level $>2.5 \mathrm{mIU} / \mathrm{l}$ in the first trimester or $>3 \mathrm{mIU} / \mathrm{l}$ in the second and third trimesters in conjunction with a decreased FT4 concentration, or as a TSH level R10.0mIU/l, irrespective of the FT4 level. Subclinical hypothyroidism was defined as a serum TSH level between 2.5 and $10 \mathrm{mIU} / \mathrm{l}$ and a normal FT4 level (4).

Statistical analysis was performed via SPSS software (SPSS, Chicago, IL, USA). Continuous variables were compared using student's t test (for paired data) or Mann-Whitney U test for nonparametric data. For categorical data, comparison was done using Chi-square test (X2) or Fisher's exact test when appropriate. A P value of $<0.05$ was considered statistically significant.

Ethical clearance and approval for conducting this research was obtained from Omdurman Maternity Hospital manager and informed verbal consent was obtained from every respondent who agreed to participate in the study. Of course, the respondents informed that the
Table 2: Demographic and clinical characteristics of the 410 participants Euthroid and hypothyroidism.

\begin{tabular}{|c|c|c|c|}
\hline Parameter & Euthyroid & Hypothyroidism & $P$ value \\
\hline \multicolumn{4}{|l|}{ Age (years) } \\
\hline$<20$ & $45(11.3 \%)$ & $1(07.7 \%)$ & \multirow{5}{*}{$0.000^{*}$} \\
\hline 20- 30 & $172(43.3 \%)$ & $3(23.0 \%)$ & \\
\hline $31-40$ & $147(37.1 \%)$ & $4(30.8 \%)$ & \\
\hline$>40$ & $33(08.3 \%)$ & $5(38.5 \%)$ & \\
\hline Total & $397(100.0 \%)$ & $13(100.0 \%)$ & \\
\hline \multicolumn{4}{|l|}{ Origin } \\
\hline West Sudan & $158(39.8 \%)$ & $6(46.2 \%)$ & \multirow{5}{*}{$0.001^{*}$} \\
\hline Eastern Sudan & $84(21.2 \%)$ & $2(15.4 \%)$ & \\
\hline Northern Sudan & $124(31.2 \%)$ & $2(15.4 \%)$ & \\
\hline South Sudan & $31(07.8 \%)$ & $3(23.0 \%)$ & \\
\hline Total & $397(100.0 \%)$ & $13(100.0 \%)$ & \\
\hline \multicolumn{4}{|l|}{ Education } \\
\hline Illiterate & $29(7.3 \%)$ & $3(23.0 \%)$ & \multirow{5}{*}{0.095} \\
\hline Primary & $74(18.6 \%)$ & $4(30.8 \%)$ & \\
\hline Secondary & $187(47.2 \%)$ & $5(38.5 \%)$ & \\
\hline University & $107(26.9 \%)$ & $1(07.7 \%)$ & \\
\hline Total & $397(100.0 \%)$ & $13(100.0 \%)$ & \\
\hline \multicolumn{4}{|l|}{ Party } \\
\hline PG & $44(11.1 \%)$ & $2(15.4 \%)$ & \multirow{4}{*}{$0.04^{*}$} \\
\hline Multiparty & $266(67.0 \%)$ & $7(53.8 \%)$ & \\
\hline Grand multiparty & $87(21.9 \%)$ & $4(30.8 \%)$ & \\
\hline Total & $397(100.0 \%)$ & $13(100.0 \%)$ & \\
\hline \multicolumn{4}{|l|}{ GA (weeks) } \\
\hline 5-Feb & $179(45.1 \%)$ & $5(38.5 \%)$ & \multirow{4}{*}{0.432} \\
\hline $6-9$ & $160(40.3 \%)$ & $3(23.0 \%)$ & \\
\hline 12-Oct & $58(14.6 \%)$ & $5(38.5 \%)$ & \\
\hline Total & $397(100.0 \%)$ & $13(100.0 \%)$ & \\
\hline \multicolumn{4}{|c|}{$\begin{array}{l}\text { Personal history of thyroid } \\
\text { disease }\end{array}$} \\
\hline Present & $12(3.1 \%)$ & $2(15.4 \%)$ & \multirow{3}{*}{$0.002^{*}$} \\
\hline Not present & $385(96.9 \%)$ & $11(84.6 \%)$ & \\
\hline Total & $397(100.0 \%)$ & $13(100.0 \%)$ & \\
\hline \multicolumn{4}{|c|}{ Family History of thyroid disease } \\
\hline Present & $23(5.8 \%)$ & $3(23.0 \%)$ & \multirow{3}{*}{$0.001^{*}$} \\
\hline Not present & $374(94.2 \%)$ & $10(77.0 \%)$ & \\
\hline Total & $397(100.0 \%)$ & $13(100.0 \%)$ & \\
\hline \multicolumn{4}{|c|}{ Symptoms of hypothyroidism } \\
\hline Present & $87(21.9 \%)$ & $7(53.8 \%)$ & \multirow{3}{*}{$0.001^{*}$} \\
\hline Not present & $310(78.1 \%)$ & $6(46.2 \%)$ & \\
\hline Total & $397(100.0 \%)$ & $13(100.0 \%)$ & \\
\hline \multicolumn{4}{|l|}{ BMI } \\
\hline Underweight & $48(12.1 \%)$ & $2(15.4 \%)$ & \multirow{5}{*}{$0.02^{*}$} \\
\hline Normal weight & $244(61.5 \%)$ & $2(15.4 \%)$ & \\
\hline Overweight & $56(14.1 \%)$ & $5(38.5 \%)$ & \\
\hline Obese & $49(12.3 \%)$ & $4(30.8 \%)$ & \\
\hline Total & $397(100.0 \%)$ & $13(100.0 \%)$ & \\
\hline
\end{tabular}

*Significant. 
study is not associated with experimental or therapeutic intervention while information was collected from them.

\section{Results}

Four-hundred-and-ten women were included, the age distribution ranged from 18 to 46 years with a mean (standard deviation) age of 28.65 years. The average ranges of TSH was $(0.5-6.5 \mathrm{mIU} / \mathrm{L})$ and T4 (10.5 - $20.4 \mathrm{pmol} / \mathrm{L})$ and there was slight fluctuation of the mean values of thyroid hormones according to trimester in Euthyroid pregnant women. Subclinical and overt hypothyroidism was found in $56(13.7 \%)$ of women. Forty-three women (10.5\%) had subclinical hypothyroidism, thirteen (3.2\%) had overt hypothyroidism (Table 1).

Table 2 shows the demographic and clinical characteristics of the 410 participants studied. It was observed that majority of participants were from West Sudan 158 (39.1\%) among euthyroid and 6 (46.2\%) among overt hypothyroidism with significant association between origin and overt hypothyroidism. Most of participants 192 (46.8\%) were secondary school, majority of participants were multiparty 266 (67.0\%) among euthyroid and 7 (53.8\%) among overt hypothyroidism with significant association between party and overt hypothyroidism, majority of participants were without personal history of thyroid disease 385 (96.9\%) among euthyroid and 11 (84.6\%) among overt hypothyroidism with significant association between personal history of thyroid disease and overt hypothyroidism, family history of thyroid disease are present among 23 (5.8\%) of euthyroid participants and among 3 (23.0\%) of overt hypothyroidism.

Table 3 showed history of bad obstetric performance and risk factors associated with euthyroid and overt hypothyroidism, most of participants 229 (55.9\%) were had vaginal delivery. The current study showed significant association between overt hypothyroidism and history of infertility, history of miscarriage, stillbirth, preterm deliveries, BMI and iodine deficiency at $\mathrm{p}$. value $<0.05$.

\section{Discussion}

Hypothyroidism in pregnancy remains one of maternal medical disorders that has adverse maternal and fetal outcome in pregnant women, including miscarriage, preterm delivery, eclampsia, preeclampsia, and placental abruption benefits of early diagnosis and treatment will optimize the maternal and fetal outcomes. Therefore this study was carried out in pregnant women during $1^{\text {st }}$ trimester who attended antenatal clinic of Omdurman maternity hospital to know the correlation of hypothyroidism and pregnancy, rate, risk factors and pattern of hypothyroidism among pregnant women.

Our study showed that subclinical and overt hypothyroidism was found in (13.7\%) of women. Forty-three women (10.5\%) had subclinical hypothyroidism and (3.2\%) had overt hypothyroidism. This result is going with the fact that Subclinical hypothyroidism (elevated TSH, normal free T4) is far more common than overt hypothyroidism, occurring in 2 to 2.5 percent of screened women in the US (iodine sufficient region) [13]. A study on the prevalence of subclinical hypothyroidism in Jordanian women showed that a prevalence of $20.8 \%$ [14], which is higher than our study. This may be explained by improvement in the awareness of the community about thyroid dysfunction during pregnancy. Also our data demonstrated that the prevalence of overt hypothyroidism which was defined as a
Table 3: History of bad obstetric performance and risk factors associated with euthyroid and overt hypothyroidism among 410 participants.

\begin{tabular}{|c|c|c|c|}
\hline Parameter & Euthyroid & Hypothyroidism & $P$ value \\
\hline \multicolumn{4}{|c|}{ Previous mode of delivery } \\
\hline SVD & $223(56.2 \%)$ & $6(46.2 \%)$ & \multirow{5}{*}{0.165} \\
\hline IVD & $34(8.6 \%)$ & $0(0.0 \%)$ & \\
\hline $\mathrm{C} / \mathrm{S}$ & $93(23.4 \%)$ & $3(23.0 \%)$ & \\
\hline No previous delivery & $47(11.8 \%)$ & $4(30.8 \%)$ & \\
\hline Total & $397(100.0 \%)$ & $13(100.0 \%)$ & \\
\hline \multicolumn{4}{|c|}{ Previous outcome } \\
\hline SB & $52(13.1 \%)$ & $3(23.0 \%)$ & \multirow{3}{*}{$0.001^{*}$} \\
\hline Alive & $345(86.9 \%)$ & $10(77.0 \%)$ & \\
\hline Total & $397(100.0 \%)$ & $13(100.0 \%)$ & \\
\hline \multicolumn{4}{|c|}{ History of miscarriages } \\
\hline Yes & $89(22.4 \%)$ & $6(46.2 \%)$ & \multirow{3}{*}{$0.04^{*}$} \\
\hline No & $308(77.6 \%)$ & $7(53.8 \%)$ & \\
\hline Total & $397(100.0 \%)$ & $13(100.0 \%)$ & \\
\hline \multicolumn{4}{|c|}{ History of preterm birth } \\
\hline Yes & $92(23.2 \%)$ & $7(53.8 \%)$ & \multirow{3}{*}{$0.03^{*}$} \\
\hline No & $305(76.8 \%)$ & $6(46.2 \%)$ & \\
\hline Total & $397(100.0 \%)$ & $13(100.0 \%)$ & \\
\hline \multicolumn{4}{|c|}{ History of infertility } \\
\hline Yes & $43(10.8 \%)$ & $4(30.8 \%)$ & \multirow{3}{*}{$0.001^{*}$} \\
\hline No & $354(89.2 \%)$ & $9(69.2 \%)$ & \\
\hline Total & $397(100.0 \%)$ & $13(100.0 \%)$ & \\
\hline \multicolumn{4}{|c|}{ History of neck radiation } \\
\hline Yes & $65(16.4 \%)$ & $1(7.7 \%)$ & \\
\hline No & $332(83.6 \%)$ & $12(92.3 \%)$ & \multirow{2}{*}{0.415} \\
\hline Total & $397(100.0 \%)$ & $13(100.0 \%)$ & \\
\hline \multicolumn{4}{|c|}{ lodine deficient areas } \\
\hline Yes & $16(4.1 \%)$ & $7(53.8 \%)$ & \multirow{3}{*}{$0.001^{*}$} \\
\hline No & $381(95.9 \%)$ & $6(46.2 \%)$ & \\
\hline Total & $397(100.0 \%)$ & $13(100.0 \%)$ & \\
\hline
\end{tabular}

*Significant.

serum TSH level $>2.5 \mathrm{mIU} / 1$ in the first trimester or $>3 \mathrm{mIU} / \mathrm{l}$ in the second and third trimesters in conjunction with a decreased FT4 concentration, or as a TSH level R10.0mIU/l, irrespective of the FT4 level was (3.2\%). Our data is comparable to study done at in 2015 by Saeed and her colleagues where $(2.8 \%)$ of participants diagnosed as hypothyroidism for the first time during pregnancy [15]. Moreover, our data demonstrate rate of overt hypothyroidism higher than that reported from most countries in European (2.2\%) and American pregnant women $(2.5 \%)$ [16]. A comparison of our data with these reports is difficult because of the different criteria used, the different age groups studied, and the different methodologies adopted.

In the present study, older women were more likely to have hypothyroidism than younger. Previous reports were variable regarding age differences in the prevalence of hypothyroidism. Our data are consistent with those reported from Italy which demonstrated 
that, the prevalence of subclinical hypothyroidism in an elderly group in Italy was $6.7 \%$ [17], which was higher than $3.8 \%$ in any other age group in that country [18].

As we are going through the other risk factors we find that more than half (53.8\%) of our overt hypothyroidism patients had history of living in iodine deficient areas and the study demonstrate strong association between iodine deficiency and overt hypothyroidism (P. value 0.001 ), this may be due to the imbalance between the intake and increased requirements for iodine during gestation and results eventually in a reduced circulating maternal thyroxin. Our finding correlates with Abalovich $\mathrm{M}$ and his colleagues, which states that (while severe endemic ID can lead to $\mathrm{OH}$, mild-to moderate ID is more frequently associated with isolated hypothyroxinemia rather than $\mathrm{OH}$. Currently, 30 countries worldwide are considered iodine deficient) [19].

With regard to other risk factors of overt hypothyroidism, racial differences [20], have also been suggested. Our finding correlates with Hollowell JG and his colleagues [20], and find that majority (46.2\%) of our overt hypothyroidism patients were from West Sudan and showed a significant association between race and overt hypothyroidism. This finding clearly explain that West of Sudan are iodine deficient area, which consider to be risk factor for hypothyroidism this is supported by the finding of a randomized trial and several population-based studies of women living in severely iodine deficient regions, iodine supplementation to women prior to conception or during early pregnancy was associated with substantially better neurologic and developmental outcomes in children [21,22]

The current study showed significant association between hypothyroidism and history of infertility, history of miscarriage, stillbirth. Our result was similar to Allan et al., who demonstrated an increased risk of fetal loss and miscarriage in patients with hypothyroidism [23]. This is also supported by the findings from Saeed et al. Where their study demonstrated significant association between thyroid dysfunction and history of miscarriage [15].

In contrast to the current study, another study revealed that, stillbirth, preterm delivery and infertility have no significant association with thyroid dysfunction [15]. The discrepancy between our study and this study can be explained by multiple factors such as in our study, we only evaluated hypothyroidism, while, Saeed et al. Evaluated all thyroid dysfunction. Others explanation for such difference may be due to different criteria used, the different age groups studied, and the different methodologies adopted.

\section{Conclusion}

Our study demonstrated a high prevalence of hypothyroidism among Sudanese pregnant women. Iodine deficiency, old age, family history of thyroid diseases and ethnicity are risk factors for overt hypothyroidism. Understanding the prevalence and risk factors of hypothyroidism during pregnancy could be a help to identify the patients for screening and/or follow-up. Universal screening of pregnant women for thyroid dysfunction should thus be adopted throughout Sudan.

\section{References}

1. Beastall GH. Interpretation of thyroid function tests. UK guidelines for the use of thyroid function tests updated. 2008. London, British Thyroid Association.
2006.

2. Le Beau SO, Mandel SJ. Thyroid disorders during pregnancy. Endocrinology and Metabolism Clinics of North America. 2006; 35: 117-136.

3. Park K. Park's Text Book of Preventive and Social Medicine. $21^{\text {st }}$ edition, Jabalpur, India: Barnarsidas Bhanot. 2011; 576-577.

4. Stagnaro-Green A, Abalovich M, Alexander E, Azizi F, Mestman J, Negro R, et al. Guidelines of the American Thyroid Association for the diagnosis and management of thyroid disease during pregnancy and postpartum. Thyroid. 2011; 21: 1081-1125.

5. Tuija Mannisto, Marja Vaarasmaki, et al. Thyroid dysfunction and maternal morbidity. J Clin Endocrinol Metab, 2010; 95: 1084-1094.

6. Leung AS, Millar LK, Kooning PP, Montorom, Mestman J. Perinatal outcome in hypothyroid pregnancies. Obstetric Gynaecology. 1993; 81: 349-353.

7. LE Davis, KJ Leveno, FG Cunningham. Hypothyroidism complicating pregnancy. Obstetrics and Gynecology. 1988; 72: 108-112.

8. S Leung, LK Millar, PP Koonings, M Montoro, JH Mestman. Perinatal outcome in hypothyroid pregnancies. Obstetrics and Gynecology. 1993; 81: 349-353.

9. Garber JR, Cobin RH, Gharib H, Hennessey JV, Klein I, Mechanick JI, et al. Clinical practice guidelines for hypothyroidism in adults: co-sponsored by American Association of Clinical Endocrinologists and the American Thyroid Association. Endocrine Practice. 2012; 18: 988-1028.

10. Dufour DR. Laboratory tests of thyroid function, uses and limitations Endocrinology and Metabolism Clinics of North America. 2007; 36: 579-594.

11. Baskin HJ, Cobin RH, Duick DS, Gharib H, Guttler RB, et al. American Association of Clinical Endocrinologists medical guidelines for clinical practice for the evaluation and treatment of hyperthyroidism and hypothyroidism. Endocrine Practice. 2002; 8: 457-469.

12. Surks MI, Ortiz E, Daniels GH, Sawin CT, Col NF, Cobin RH, et al. Subclinical thyroid disease: scientific review and guidelines for diagnosis and management. Journal of the American Medical Association. 2004; 291: 228238.

13. Allan WC, Haddow JE, Palomaki GE, Williams JR, Mitchell ML, Hermos RJ, et al. Maternal thyroid deficiency and pregnancy complications: implications for population screening. J Med Screen. 2000; 7: 127-130.

14. Alkafajei A, Amarin Z, AlazaizehW, Khader Y, Marji M. Prevalence and risk factors for hypothyroidism in Jordanian women: comparison between different reference ranges. Eastern Mediterranean Health Journal. 2012; 18: 132-136.

15. Amel K Saeed, Khalid Yassin, Elmahdi MA. Elmahdi, Druce Maralyn, Abdel Aziem A Ali, et al. The Prevalence of Thyroid Dysfunction among Sudanese Pregnant Women. SOJ Gynecol Obstet Womens Health Journal. 2015; 1: 5.

16. Radi RA. Assessment of Thyroid Function in Pregnant Women from Rimal Health Center, Gaza City. 2010; 1: 1432.

17. Iervasi G, Molinaro S, Landi P, Taddei MC, Galli E, Mariani F, et al. Association between increased mortality and mild thyroid dysfunction in cardiac patients. Arch Intern Med. 2007; 167: 1526-1532.

18. Aghini-Lombardi F, Antonangeli L, Martino E, Vitti P, Maccherini D, Leoli F, et al. The spectrum of thyroid disorders in an iodine-deficient community: the Pescopagano survey. J Clin Endocrinol Metab. 1999; 84: 561-566.

19. Abalovich M, Amino N, Barbour LA, Cobin RH, De Groot LJ, Glinoer D. Management of thyroid dysfunction during pregnancy and postpartum: an Endocrine Society Clinical Practice Guideline. J Clin Endocrinol Metab. 2007; 92: S1-47.

20. Hollowell JG, Staehling NW, Flanders WD, Hannon WH, Gunter EW Spencer CA, et al. Serum TSH, T(4), and thyroid antibodies in the United States population (1988 to 1994): National Health and Nutrition Examination Survey (NHANES III). J Clin Endocrinol Metab. 2002; 87: 489-499.

21. Cao XY, Jiang XM, Dou ZH, Rakeman MA, Zhang ML, O'Donnell K, et al. Timing of vulnerability of the brain to iodine deficiency in endemic cretinism. N Engl J Med. 1994; 331: 1739-1744. 
22. Qian M, Wang D, Watkins WE, Gebski V, Yan YQ, Li M, et al. The effects of iodine on intelligence in children: a meta-analysis of studies conducted in China. Asia Pac J Clin Nutr. 2005; 14: 32-42.
23. Allan WC, Haddow JE, Palomaki GE, Williams JR, Mitchell ML, Hermos RJ, et al. Maternal thyroid deficiency and pregnancy complications: implications for population screening, Journal of Medical Screening. 2000; 7: 127-130.
Austin J Obstet Gynecol - Volume 5 Issue 7 - 2018

Submit your Manuscript | www.austinpublishinggroup.com

Elwahid Suliman et al. @ All rights are reserved
Citation: Abd Elwahid Suliman AA, Albasha MA, Ibrahim3 HS, Handady SOM, Alawad AAM. Rate, Pattern and Risk Factors of Hypothyroidism among Sudanese Pregnant Women. Austin J Obstet Gynecol. 2018; 5(7): 1121. 